\title{
Editorial
}

\section{Abusos na escola médica}

Boa parte da sociedade brasileira se surpreendeu negativamente com a divulgação das denúncias sobre práticas violentas ocorridas no âmbito de uma tradicional escola médica paulista. Violência moral e sexual, com temperos sexistas, racistas e homofóbicos. Nós também ficamos surpresos e entendemos que esta é mais uma oportunidade para a reflexão desarmada sobre essas questões e outras mais, dentro do mesmo amplo tema.

Há cerca de 8 anos publicamos aqui um editorial1 sob o título de "Bullying: mais uma epidemia invisível?" Nele buscávamos dar visibilidade para a discussão sobre a violência na escola médica e a necessidade de se empreender um esforço consciente para encontrar meios de controlá-la e superá-la. Embora a questão do trote fosse uma das mais perceptíveis naquela época, queríamos destacar que a violência já não se restringia às questões do trote. Preocupava-nos sobremaneira o assédio moral. Naquela época comentamos os resultados de uma pesquisa multicêntrica realizada sob os auspícios da Organização Internacional do Trabalho e que desvelou a violência nos ambientes de trabalho da saúde, mundo afora. Violência essa que não se restringia àquela entre pacientes e acompanhantes e equipe, mas incluía também a entre colegas e referia-se à violência moral, sexual e até mesmo física, embora de menor monta ${ }^{1}$..

Mister é buscar as raízes desses comportamentos não apenas nos padrões de organização do trabalho, mas também no processo de formação desses profissionais. Assim, entendemos que não é o caso de nos determos apenas nos fatos recentemente denunciados pelos alunos da USP, mas entende-lo como um fenômeno muito mais amplo, que acontece não apenas em outras escolas médicas nacionais, como em todo o mundo. Recentemente foi publicado no blog do The New York Times um artigo importantíssimo de uma médica com o título "The bullying culture of medical school”2. Lá ela menciona que o processo de formação, para muitos estudantes de medicina, não se refere apenas a superar os desafios acadêmicos, mas também os abusos e intimidações, de professores e colegas. Naquele mesmo ano, quatro dias depois, o "American Medical Newws", então publicado pela Associação Médica Americana, publicou o artigo de $\mathrm{Krupa}^{3}$, "Longtime culture of mistreating students persists at med schools onde ela comenta os resultados da pesquisa nacional com formandos de todas as escolas médicas estadunidenses realizada pela Association of American Medical Colleges (AAMC), que detalham maus tratos sofridos por $47 \%$ dos 12195 respondentes, dos quais apenas $17 \%$ relataram o acontecimento para a direção da escola. O abuso mais frequentemente descrito era a humilhação pública, mas o sexismo também foi bem mencionado. Já o blog do Professor Maurice Bernstein, da Universidade da California em Los Angeles incluiu, no dia 10 de agosto de 2004, o tópico "Medical Student Abuse" ${ }^{\text {, }}$, no qual são apresentados, na primeira pessoa, depoimentos de estudantes que sofreram abusos, sendo que alguns chegaram a abandonar seus estudos. Se incluímos essas referências aqui é para ressaltar que os problemas de violência na escola médica não se restringem aos gravíssimos fatos recém denunciados pelos estudantes da USP e, 
obviamente, não se restringem a essa escola. Também é preciso que se enfrente o problema de frente, reconhecendo que não se trata apenas e tão somente de agressões e abusos entre estudantes, mas também envolve, ou pode envolver, docentes. É preciso reconhecer a cultura do abuso, para que possamos formular políticas e estratégias de controle. Nas palavras de Fried, autora do estudo da AAMC, "as pessoas estão estressadas e esgotadas. A medicina acadêmica é difícil. Demanda muito dos professores. Eles ganham menos dinheiro e trabalham duro. As pessoas estão cansadas e tratam mal os estudantes, infelizmente, porque eles podem. Essa é a cultura há décadas." ${ }^{3}$ Mesmo no Chile,

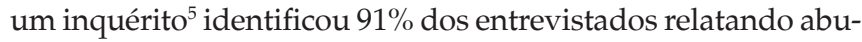
sos, cometidos por professores e colegas mais velhos.

No Brasil temos focado bastante nos problemas do relacionamento entre estudantes, que é efetivamente muito sério, e tem levado a realização de estudos específicos e a formulação de políticas relacionadas com o trote ${ }^{6}$. Sabe-se que os resultados, nas diversas escolas médicas no Brasil, ainda não são totalmente animadores, mas parte da comunidade acadêmica médica está se mobilizando. Este ano, por exemplo, tivemos a violência médica como tema da reunião da regional São Paulo de nossa Abem, em fevereiro. Estamos no caminho, mas precisamos incluir os ambientes da escola médica como um todo em nosso escopo de atenção. Precisamos conhecer, analisar e combater o assédio moral seja de docentes, membros do staff ou mesmo residentes. Não nos cabe mais ignorar os abusos, mas temos que implementar políticas de combate à cultura do abuso, seja quem for o perpetrador dele. É preciso mobilizarmos a gestão, os docentes, staffs e discentes das escolas médicas para formulação e implementação dessas políticas, entendendo que todos os envolvidos devem ser convocados a participar e quando se trata de violência em ambientes de trabalho e ensino não basta afastar parte da violência - toda ela precisa ser banida.

Fried e seus colegas ${ }^{7}$ relataram as ações empreendidas pela UCLA, desde 1995, com a criação de políticas para prevenir abusos, mecanismos seguros para denuncia-los e processos educativos para preparar docentes e residentes sobre a questão. Vê-se que as políticas a serem empreendidas são amplas, multifacetadas, uma vez que a complexidade do problema demanda identificar, registrar, educar, cuidar e por último punir. Cada um desses aspectos demandam diversas ações de cada um desses segmentos que compõem a escola. Mostra da dificuldade de se tratar do tema, mostra de que não há um modelo a ser seguido, que cada escola médica precisa se debruçar sobre o assunto e desenvolver suas políticas e ações, é que apesar da mobilização empreendida pela UCLA por mais de 15 anos, reconhecem que não conseguiram ainda erradicar os abusos e creditam ao currículo oculto as razões.
É preciso combater a cultura do abuso na escola médica e, para tal, precisamos reconhecer que o problema não está restrito ao relacionamento entre alunos, mas se estende para a relação entre docentes e discentes e mesmo entre quaisquer outros atores presentes no ambiente universitário (incluindo colegas docentes ou membros do staff). Mas precisamos também conhecer o problema a fundo, utilizando-se de estratégias de pesquisa que nos ajude a entender os diversos aspectos do problema e, especialmente, conhecer sua atual dimensão e complexidade.

A formação deve estar voltada para a difusão da cultura do respeito aos direitos humanos e fortalecimento das estratégias de diálogo, sem o quê nem os primeiros passos para que preparemos nossos alunos para lidarem com um mercado de trabalho cada vez mais despersonalizante e alienante terá sido dado, nem muito menos ser atendido o preconizado nas Diretrizes Curriculares para o Curso de Medicina. A cultura do respeito e do diálogo deve prevalecer em nossas escolas e técnicas e métodos de ensino precisam ser considerados à luz de seus impactos para sua difusão.

\section{REFERÊNCIAS}

1. Palacios M \& Rego S. Bullying: mais uma epidemia invisível?. Rev. bras. educ. med. [online]. 2006, vol.30, n.1 [citado 2014-12-05], pp. 3-5 . Disponível em: <http:// www.scielo.br/scielo.php?script=sci_arttext\&pid=S0100$-55022006000100001 \& \operatorname{lng}=$ pt\&nrm=iso $>$. ISSN 0100-5502. http:/ /dx.doi.org/10.1590/S0100-55022006000100001.

2. Chen PW The bullying culture of medical school Disponível em http://well.blogs.nytimes.com/2012/08/09/the-bullying-culture-of-medical-school/?_r=0 Published on AUGUST 9, 2012. Consulta em 04/12/2014.

3. Krupa C. Longtime culture of mistreating students persists at med schools http://www.MEDNEWS.COM/APPS/PBCS. DLL/PERSONALIA?ID=CKRUPA Posted Aug, 13 - 2012)

4. Bernstein M. Medical Student Abuse In: Bioethics discussion blog. Published on 10 de agosto de 2004 " Acesso em 05/12/2014.

5. Maida AM, Herskovic V, Pereira A, Salinas-Fernández L, Esquivel C. Percepción de conductas abusivas en estudiantes de medicina Rev Méd Chile 2006; 134: 1516-1523)

6. Ver, por exemplo, artigos aqui mesmo na Rbem e Akerman M (Org.); Conchao, S. (Org.) ; Boaretto RC. (Org.) . "Bulindo" com a Universidade: um estudo sobre o trote na Medicina. 1a. ed. São Paulo: Hucitec, 2012. 174p.

7. Fried JM, Vermillion M, Parker NH, Uijtdehaage S. Eradicating Medical Student Mistreatment: A Longitudinal Study of One Institution's Efforts Academic Medicine, Vol. 87, No. 9 / September 2012. 